\title{
Bayesian multilevel model application on determinants of perinatal mortality in Ethiopia using 2011 and 2016 EDHS data
}

\author{
Berhanu Bekele Debelu ${ }^{1}$, Denekew Bitew Belay ${ }^{2,}$, Nigatu Degu Terye ${ }^{3}$ \\ ${ }^{1}$ Wolkite University, Department of Statistics, Wolkite, Ethiopia \\ ${ }^{2}$ Bahir Dar University, Department of Statistics, Bahir Dar, Ethiopia \\ ${ }^{3}$ Hawassa University, Department of Statistics, Hawassa, Ethiopia
}

\begin{abstract}
Perinatal mortality is the death of a fetus after the age of viability until the $7^{\text {th }}$ day of life. Perinatal mortality is estimated by the addition of stillbirths plus the early neonatal mortality, which represents deaths occurring during the first 7 days after delivery. Perinatal mortality remains a great burden in Ethiopia. The purpose of this study was to assess and compare the demographic and socio-economic determinant factors of perinatal mortality in Ethiopia using the 2011 and 2016 Ethiopian Demographic Health Surveys (EDHS). For data analysis, the Bayesian multilevel Model was used in this study. The study revealed that there is a regional variation in perinatal mortality and this variation was high in 2011 EDHS than in 2016 EDHS data. Factors like sex of the child, age of mother, wealth index, family size, birth order, source of drinking water, place of residence, place of delivery, and child twin were found to be the determinant factors of perinatal mortality in both 2011 and 2016 EDHS. In this study, we found that perinatal mortality variation across regions has decreased from 2011 to 2016 surveys which shows the promising progress of health intervention in the country.
\end{abstract}

Keywords: Perinatal Mortality, Regional Variations,Bayesian Multilevel Modeling DOI: https://dx.doi.org/10.4314/ejst.v14i1.3

\section{INTRODUCTION}

Perinatal mortality (PNM) is the death of fetus after the age of viability until the $7^{\text {th }}$ day of life. It is estimated by the addition of stillbirths plus the early neonatal mortality, which represents deaths occurring during the first seven days after delivery. The Perinatal mortality rate (PNMR) is one of the best indicators of the health status of a population in general. It is defined as a period between 22 weeks

\footnotetext{
*Corresponding author: denekew.t.h@gmail.com
}

CThis is an Open Access article distributed under the terms of the Creative Commons Attribution License (http://creativecommons.org/licenses/CC BY4.0) 
of gestation and seven days after live birth (Siddalingappa et al., 2013). Sociodemographic factors, general health status, as well as availability and quality of medical care associate with pregnancy outcomes and the impact of these factors on perinatal mortality varies within and between countries (Usynina et al., 2017) .

There are considerable differences in perinatal mortality rate between developed and developing countries. The perinatal mortality occurring in this period is largely due to obstetric causes. More than 3.3 million stillbirths and over 3 million early neonatal deaths are estimated to take place every year. In 2000 , over 6.3 million perinatal deaths occurred worldwide: almost all of them $(98 \%)$ occurred in developing countries and $27 \%$ in the least developed countries. In developing countries stillbirths represent more than half of perinatal deaths, while in developed countries, where interventions have largely eliminated excess early neonatal mortality, over 6 out of 10 perinatal deaths are stillbirths. More than one third of stillbirths take place intrapartum, i.e., during delivery, and are largely avoidable. The perinatal mortality rate is five times higher in developing than in developed regions: 10 deaths per 1000 total births in developed regions; 50 per 1000 in developing regions and over 60 per 1000 in least developed countries. It is highest in Africa, with 62 deaths per 1000 births, and especially in middle and western Africa, which have rates as high as 75 and 76 per 1000 . The perinatal mortality rate in Asia is 50 per 1000 total births, with a peak of 65 per 1000 in South-central Asia (WHO, 2006). Many demographers and scholars do believe and recommend that, the need to conduct in depth studies on the various aspects of infant and child health status in a different demographic, economic, and social-cultural setting. Perinatal mortality which includes stillbirth has received less global attention despite being most common in low-middle income countries. Although there is reduction in the perinatal mortality, it is still high in Sub-Saharan Africa and South Asia. In SubSaharan africa, approximately 30 million women become pregnant in a year and of those, about 1 million deliveries are stillbirth; at least 1 million babies die in their first month of life and 0.5 million die on the first day (Mihiretu Negash and Elazar Tadesse, 2017). The magnitude of perinatal mortality in Ethiopia was among the highest in Sub Saharan Africa. Ethiopia suffers from high perinatal mortality like most Sub-Saharan Africa countries. Most of the contributing factors for mortality in Ethiopia are health care service related (Yirgu Robel, 2016). According to the Demographic Health Survey in Ethiopia perinatal mortality rate was 52 per 1000 births in 2000, 37 per 1000 births in 2005, 46 per 1000 births in 2011 and 33 per 1,000 births in 2016 (Central Statistical Agency, 2016). The overall perinatal mortalities reported from ten hospital based studies in Ethiopia were in the range of 66 to 124 per 1000 births which implies proportion of stillbirths and early neonatal deaths reported from the hospital based and community based studies was very high (Mihiretu Negash and Elazar Tadesse, 2017). The objective of this study was to identify the effects of the demographic and socio-economic determinant factors of perinatal mortality in Ethiopia and compare the regional variation of perinatal mortality in the two consecutive Survey data. 


\section{METHODS}

\section{Data description}

The data used for this study was the two EDHS surveys and the sampling technique is stated in Ethiopian Statistical Agency (2011). The variable of interest in this study was perinatal mortality, and it has been dichotomized as 1 indicating one or more perinatal mortality occcured or 0 for no mortality. The explanatory variables have been selected considering all dimensions of perinatal mortality in Ethiopia which includes demographic factors, such as sex of child, age of mothers, birth order, child twin and family size, socio-econimic factors, such as wealth index, educational level, place of residence, place of delivery, religion and region and environmental factors, such as source of drinking water, use of contraceptives, smoking cigarettes have been included in the study (Ashenafi Senbeta et al., 2016).

\section{Multilvel model}

We employed multilevel modeling approach in a Bayesian setting as it is appropriate for hierarchical sampling procedure, like the EDHS data. The main category of multilevel analysis is the hierarchical generalized linear model which is an extension of the generalized linear model that includes nested random coefficients. Hierarchical modeling explicitly accounts for the clustering of the units of analysis, individuals nested within groups. Such data structures are viewed as a multistage sample from a hierarchical population. In this data structure, level-1 is the women and level-2 is the region (Hox et al., 2010). We have applied a Bayesian approach which incorporates our prior beliefs that are of interest to see the additional information obtained from these prior distributions (Hoff, 2009). The statistical models applied in this paper are Bayesian Empty multlevel model, Bayesian random intercept multilevel model and Bayesian random coefficient multilevel models and their details are discussed below.

\section{Bayesian Multilevel Empty Model}

The empty two-level model for a binary response variable refers to a population of groups (level two units) and specify the probability distribution for group dependent probabilities without taking further explanatory variables into account (Sinha et al., 1999). The logit linear predictor is given as:

$$
\operatorname{logit}\left(\pi_{i j}\right)=\beta_{0}+U_{0 j}
$$


Where $\pi_{i j}=\frac{e^{\beta_{0}+U_{0 j}}}{1+e^{\beta_{0}+U_{0 j}}}$ and the deviation $U_{0 j}$ are assumed normal distribution with mean zero and variance $\sigma_{0}^{2}$.

Likelihood Function: Statistical inferences are usually based on maximum likelihood estimation (MLE). The likelihood contribution from the $i^{\text {th }}$ woman in the $\mathrm{j}^{\text {th }}$ region is Bernoulli; which is given as follows;

$$
L\left(\pi_{i j}=y_{i j}\right)=\prod_{j} \pi_{i j}^{y_{i j}}\left(1-\pi_{i j}\right)^{1-y_{i j}}
$$

Prior Distribution: The prior distribution is a probability distribution that represents the prior information associated with the parameters of interest. We assumed a uniform prior distribution for $\beta_{0}$ and gamma distribution with parameter alpha $(\alpha)$ and theta $(\theta)$ for precision parameter $\left(\sigma_{0}^{-2}\right)$.

$P\left(\beta_{0}\right) \sim$ uniform distribution (1)

$P\left(\sigma_{0}^{-2}\right) \sim \operatorname{Gamma}(\alpha, \theta)$; where, $\alpha$ and $\theta$ are fixed constant parameter.

Posterior Distribution: The full conditional distribution for parameter $\beta_{0}$ is

$$
p\left(\beta_{0} / \sigma_{u}, y_{i j}\right) \propto \prod_{j}\left(\frac{e^{\beta_{0}+U_{0 j}}}{1+e^{\beta_{0}+U_{0 j}}}\right)^{y_{i j}}\left(\frac{1}{1+e^{\beta_{0}+U_{0 j}}}\right)^{1-y_{i j}} .
$$

For the second parameter of $\sigma_{0}$, the full conditional distribution of posterior for parameter from the given likelihood and prior distribution is follow the gamma distribution. This implied that, the prior is the conjugate prior and the posterior is given as:

$$
P\left(\sigma_{0^{-}}{ }^{2} / \beta_{0, y_{i j}}\right) \sim \operatorname{Gamma}(n / 2+n(\alpha-1), n \theta)
$$

where $\mathrm{n}$ is the total number of women interviewed which is the sum of $n_{j}$. We have also computed intraclass correlations to account the degree of resemblance of perinatal mortality occurrence between level I units (women) belonging to the same region. It is an indication of the proportion of variance at the second level (region) and it can also be interpreted as the expected correlation between two randomly chosen individuals within the same group and it measures the proportion of variance in the outcome explained by the grouping structure.

$$
I C C=\frac{\sigma_{u_{0}}^{2}}{\sigma_{u_{0}}^{2}+\sigma_{e}^{2}}
$$

Where $\sigma_{e}^{2}=\frac{\pi^{2}}{3}=3.29$ (Sinha et al., 1999). 


\section{Bayesian random intercept multilevel model}

In the random intercept multilevel regression model the intercept is the only random effect that the groups (regions) differ with respect to the average value of the response variable. But the relation between explanatory and response variables can differ between groups (regions). We assume that there are variables which potentially explain the observed success and failure. These variables are denoted by $X_{h}, \mathrm{~h}=1,2, \ldots, \mathrm{k}$ with their values indicated by $X_{h i j}$. Since some or all of those variables could be level one variable, the success probability is not necessarily the same for all individual in a given group (Sinha et al., 1999; Khan and Shaw, 2011). The logit of $\pi_{i j}$ is a sum of linear function of explanatory variables and given as:

$\operatorname{Logit}\left(\pi_{i j}\right)=\log \left[\frac{\pi_{i j}}{1-\pi_{i j}}\right]=\beta_{0 \mathrm{j}}+\beta_{1} \mathrm{X}_{1 \mathrm{ij}}+\ldots+\beta_{\mathrm{k}} \mathrm{X}_{\mathrm{ijk}}$

Where the intercept term $\beta_{0 j}$ is assumed to vary randomly and is given by the sum of an average intercept $\beta_{0}$ and region-dependent deviations $U_{0 j}$, that is $\beta_{0 j}=\beta_{0}+U_{0 j}$

$\operatorname{logit}\left(\pi_{i j}\right)=\beta_{0}+\sum_{h=1}^{k} \beta_{h j} x_{h i j}+U_{0 j}$

where $\beta_{0}+\sum_{h=1}^{k} \beta_{h j} x_{h i j}$ is the fixed part of the model and $U_{0 j}$ is the random part. The $\pi_{i j}$ is given as:

$$
\pi_{i j}=\frac{e^{\beta_{0^{+}} \sum_{h=1}^{k} \beta_{h j} x_{h i j}+U_{0 j}}}{1+e^{\beta_{0 j^{+}} \sum_{h=1}^{k} \beta_{h j} x_{h i j}+U_{0 j}}}
$$

\section{Bayesian random coefficient multilevel model}

The multilevel analogue random coefficient logistic regression is based on linear models for the log odds that include random effects for the groups or other higher level units. Consider explanatory variables which are potential explanations for the 
observed outcomes. The values of $X_{h}(\mathrm{~h}=1,2,3, \ldots, \mathrm{k})$ are indicated in the usual way by $X_{h i j}$, since some or all of these variables could be level one variables. The success probability depends on the individual as well as the group, and is denoted by $\pi_{i j}$. Now consider a model with group specific regression of logit of the success probability logit $\left(\pi_{i j}\right)$ on a single level one explanatory variables X (Sinha et al., 1999; Johnson, 2010).

$\operatorname{logit}\left(\pi_{i j}\right)=\log \left[\frac{\pi_{i j}}{1-\pi_{i j}}\right]=\beta_{0}+\sum_{h=1}^{k} \beta_{h j} x_{h i j}+U_{0 j}+\sum_{h=1}^{k} U_{h j} x_{h i j}$

The term $\sum_{h=1}^{k} U_{h j} x_{h i j}$ can be regarded as a random interaction between group and the explanatory variables. The deviation $U_{h j}$ are assumed normal distribution with mean zero and variance covariance matrix $\Omega$. This model implies that the groups are characterized by two random effects: their intercepts and their slopes. It assumes that, for different groups the pairs of random effects $\left(U_{0 j}, U_{h j}, \mathrm{~h}=1,2, \ldots, \mathrm{k}\right)$ are independent and identically distributed. The random intercept variance, $\operatorname{Var}\left(U_{0 j}\right)=\sigma_{0}^{2}$, the random slope variance, $\operatorname{Var}\left(U_{1 j}\right)=\sigma_{1}^{2}$ and the covariance between the random effects, $\operatorname{Cov}\left(U_{0 j}, U_{1 j}\right)=\sigma_{01}^{2}$ are called variance components (Sinha et al., 1999; Johnson, 2010).

Likelihood Function: Assume $\left(y_{i j} / \pi_{i j}\right) \propto \operatorname{Bernoull}\left(\pi_{i j}\right)$

Let us denote the likelihood function like $L\left(y_{i j}, \pi_{i j}\right)$ and written as follows;

$$
L\left(\pi_{i j} / y_{i j}\right)=\prod_{i j}\left(y_{i j} / \pi_{i j}\right) \text { and the linear predictor or the logit function }
$$
is,

$$
\begin{aligned}
& \operatorname{logit}\left(\pi_{i j}\right)=\log \left[\frac{\pi_{i j}}{1-\pi_{i j}}\right]=\beta_{0 j}+\sum_{h=1}^{k} \beta_{h j} x_{h i j}+U_{0 j}+\sum_{h=1}^{k} U_{h j} x_{h i j}, \\
& \text { Where, } \pi_{i j}=\frac{e^{\beta_{0 j^{+}} \sum_{h=1}^{k} \beta_{h j} x_{h i j}+U_{0 j^{+}} \sum_{h=1}^{k} U_{h j} x_{h i j}}}{1+e^{\beta_{0 j^{+}} \sum_{h=1}^{k} \beta_{h j} x_{h i j}+U_{0 j}+\sum_{h=1}^{k} U_{h j} x_{h i j}}}
\end{aligned}
$$


Prior Distribution: Let us denote the prior distribution of parameters $\beta_{0}, \beta_{1}, \ldots, \beta_{k}$ and $\Omega_{u}$ as follows:

$$
\begin{aligned}
& P\left(\beta_{0}\right) \propto 1, P\left(\beta_{1}\right) \propto 1, \ldots P\left(\beta_{k}\right) \propto 1 \text { and } \\
& P\left(\Omega_{u}\right) \propto \text { inverse-wishart }\left(m^{*} S_{u}, m\right) \text { distribution. The parameter }
\end{aligned}
$$

$\Omega_{u}$ is the variance covariance matrices and $S_{u}$ is an estimate for the true value of $\Omega_{u}$ and $\mathrm{m}$ is the number of rows in the variance covariance matrix.

Posterior Distribution: Using the above prior and likelihood function above the the full conditional distribution of posterior parameter $\beta_{0}, \beta_{1}, \ldots \beta_{\mathrm{k}}$ is given by:

$$
\begin{aligned}
& P\left(\beta_{h} / \Omega_{u}, U_{0 j}, y_{i j}\right) \propto \prod_{i j}\left(\left(\pi_{i j}^{y_{i j}}\right)\left(1-\pi_{i j}\right)^{1-y_{i j}}\right) \\
& \quad \text { Where } \mathrm{h}=1,2, . ., \mathrm{k} \text { and } \\
& P\left(\Omega_{u} / \beta_{h}, U_{0 j}, y_{i j}\right) \propto P\left(y_{i j} / \Omega_{u}, \beta_{h}, U_{0 j}\right) P\left(U_{0 j} / \Omega_{u}\right) P\left(\Omega_{u}\right)
\end{aligned}
$$

The estimation technique used in this study is MCMC estimation specifically metropolis hasting algorism was used and the DIC were used for comparison of the model.

We used MH algorism, since Gibbs sampling do not have much control over the correlation of the Markov chain, but with the Metropolis algorithm the correlation can be adjusted by selecting an optimal value of $\delta$ in the proposal distribution. By selecting $\delta$ carefully, we can decrease the correlation in the Markov chain, leading to an increase in the rate of convergence, an increase in the effective sample size of the Markov chain and an improvement in the Monte Carlo approximation to the posterior distribution (Hoff, 2009).

Once a model has been developed, we would like to know how effective the model is in describing the outcome. This is referred to as goodness of fit. The most common ways of checking goodness of fit are: diagnosis for convergence and mixing and posterior-predictive check. In our study for convergence tests and goodness of fit of the model: Time series plot, Kernel density plot, Time series diagonostics, Monte Carlo standard error were used. 


\section{RESULTS}

\section{Descriptive Results}

Table 1 shows the descriptive statistics of 2011 and 2016 EDHS data of Ethiopia. Figures in square brackets (bold) are 2016 data those out of square brackets are 2011 data. The descriptive results showed that the proportion of perinatal mortality varied across different regions of Ethiopia. Gambella had the highest proportion of perinatal mortality of children, i.e., $6.5 \%$, followed by Benishangul Gumuz, 4.9\%. In 2011, Dire Dawa had the lowest proportion of mortality $(0.5 \%)$ followed by Addis Ababa (0.7\%). In 2016, Somali Region of Ethiopia had the highest proportion of child mortality $(6 \%)$ followed by Benishangul Gumuz (4.5\%). Dire Dawa had the lowest $(0.4 \%)$ mortality followed by Amhara $(0.9 \%)$.

Table 1. Descriptive statistics results for 2011 and 2016 EDHS data. (Totals for the major explanatory variables are shown as footnote*)

\begin{tabular}{|c|c|c|c|c|}
\hline \multirow[t]{2}{*}{ Variables } & \multicolumn{2}{|c|}{ Perinatal mortality } & \multicolumn{2}{|l|}{ Alive } \\
\hline & $\mathbf{N}$ & $\%$ & $\mathbf{N}$ & Percent \\
\hline \multicolumn{5}{|l|}{ Region } \\
\hline Tigray & $37[\mathbf{1 3}]$ & $3.1[\mathbf{1 . 2}]$ & $1151[\mathbf{1 0 8 3}]$ & $96.9[\mathbf{9 8 . 8}]$ \\
\hline Afar & $12[\mathbf{3 0}]$ & $1.3[3.5]$ & $925[\mathbf{8 1 7}]$ & $98.7[96.5]$ \\
\hline Amhara & $17[\mathbf{1 1}]$ & $1.2[\mathbf{0 . 9}]$ & $1374[\mathbf{1 1 3 6}]$ & $98.8[99.1]$ \\
\hline Oromia & $25[14]$ & $1.7[\mathbf{1 . 0}]$ & $1428[\mathbf{1 3 3 4}]$ & $98.3[\mathbf{9 9}]$ \\
\hline Somali & $12[61]$ & $1.8[\mathbf{6 . 0}]$ & $666[954]$ & $98.2[94]$ \\
\hline Benishangul Gumuz & $46[37]$ & $4.9[4.5]$ & $894[790]$ & $95.1[95.5]$ \\
\hline SNNPR & $13[8]$ & $1.0[0.66]$ & $1330[\mathbf{1 2 0 9}]$ & $99.0[\mathbf{9 9 . 3 4}]$ \\
\hline Gambella & $56[31]$ & $6.5[4]$ & $812[742]$ & $93.5[96]$ \\
\hline Harari & $12[7]$ & $1.7[\mathbf{1 . 2}]$ & $679[\mathbf{5 9 2}]$ & $98.3[98.8]$ \\
\hline Addis Ababa & $5[9]$ & $0.7[1.4]$ & $738[\mathbf{6 3 7}]$ & $99.3[\mathbf{9 8 . 6}]$ \\
\hline Dire Dawa & $3[3]$ & $0.5[\mathbf{0 . 4}]$ & $661[752]$ & $99.5[99.6]$ \\
\hline \multicolumn{5}{|l|}{ Sexes } \\
\hline Male & $157[\mathbf{1 4 0}]$ & $2.8[\mathbf{2 . 6}]$ & $5412[\mathbf{5 2 0 4}]$ & $97.2[97.4]$ \\
\hline Female & $81[84]$ & $1.5[1.7]$ & $5246[4846]$ & $98.5[98.3]$ \\
\hline \multicolumn{5}{|l|}{ Wealth index } \\
\hline Poor & $133[\mathbf{1 3 8}]$ & $2.9[3]$ & $4533[4466]$ & $97.1[97]$ \\
\hline Medium & $35[22]$ & $2.1[\mathbf{1 . 6}]$ & $1596[\mathbf{1 3 7 0}]$ & $97.9[\mathbf{9 8 . 4}]$ \\
\hline Rich & $70[63]$ & $1.5[\mathbf{1 . 5}]$ & $4529[4215]$ & $98.5[98.5]$ \\
\hline \multicolumn{5}{|l|}{ Place of delivery } \\
\hline Home & $92[98]$ & $3.1[2.2]$ & $2856[4320]$ & $96.9[97.8]$ \\
\hline Government hospital & $15[\mathbf{1 3}]$ & $2.6[\mathbf{1 . 5}]$ & $568[865]$ & $97.4[98.5]$ \\
\hline Private hospital & $3[2]$ & $2.6[1.2]$ & $111[\mathbf{1 6 0}]$ & $97.4[\mathbf{9 8 . 8}]$ \\
\hline Other & $128[\mathbf{1 1 1}]$ & $1.8[2.3]$ & $7123[4706]$ & $98.2[97.7]$ \\
\hline
\end{tabular}

*Totals: Regions = 10896 [10274]; sexes=10896 [10275]; wealth index =10896 [10275]; place of delivery $=10896[\mathbf{1 0 2 7 5}]$ 
Male children had higher proportion of perinatal mortality than females, which was $2.8 \%$ in 2011 and $2.6 \%$ in 2016. Similarly, poor households had high perinatal mortality, which was $2.9 \%$ in 2011 and $3 \%$ in 2016 . Rich households had the lowest perinatal mortality of $1.5 \%$. According to the place of delivery, home delivery had resulted in more perinatal mortality, with $3.1 \%$ in 2011 and $2.2 \%$ in 2016. According to the educational status of the women, the perinatal mortality was high with the minimum level of education. The highest perinatal child mortality was recorded in women with no education, which was $2.3 \%$ in 2011 and $2.4 \%$ in 2016 . Perinatal child mortality was less on women with higher education, which was $1.5 \%$.

The probability of perinatal survival agregated over regions was high in Dire Dawa as compared to other regions for both 2011 and 2016 EDHS data and the probability of perinatal survival was low for Gambella and Somali regions in 2011 and 2016, respectively (Figure 1). This indiacted that the perinatal mortality was high in Gambella in 2011 and in Somali region in 2016.

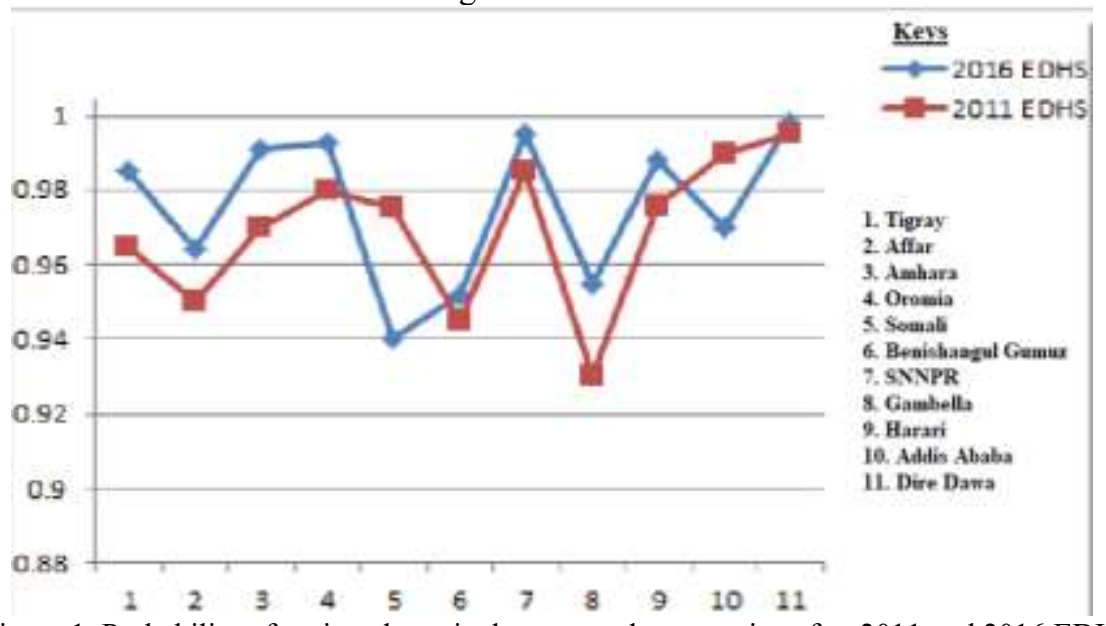

Figure 1. Probability of perinatal survival agregated over regions for 2011 and 2016 EDHS data.

\section{Bayesian multilevel empty model}

The simplest and important specifications of the hierarchical linear model is a model in which only the intercept varies between level two units and no explanatory variables are entered in the model. The empty model contains no explanatory variables and it can be considered as a parametric version of assessing heterogeneity 
of perinatal mortality among regions. The variance of the random factor is significant which indicates that there are regional differences in perinatal mortality. From the Both data showed that there was a significant variation among the regions in perinatal mortality (Table 2). The regional variation of 2011 data was 11.211 which was significantly larger than 2016 regional variation (4.247), which was also significant. Large reduction of regional variations among perinatal mortality was observed.

We have also computed intraclass correlations to understand the proportion of variation of perinatal mortality across regions.

$$
\begin{gathered}
I C C=\frac{\sigma_{u_{0}}{ }^{2}}{\sigma_{u_{0}}{ }^{2}+\sigma_{e}{ }^{2}}=\frac{11.211}{11.211+3.29}=0.7731 \text { for } 2011 \mathrm{EDHS} \\
I C C=\frac{\sigma_{u_{0}}{ }^{2}}{{\sigma_{u_{0}}}^{2}+\sigma_{e}{ }^{2}}=\frac{4.247}{4.247+3.29}=0.5635 \text { for } 2016 \mathrm{EDHS}
\end{gathered}
$$

Table 2. Bayesian multilevel empty model results using 2011 [2016] EDHS data

\begin{tabular}{lcccc}
\hline Model & Coefficient & S.E & Z-value & P-value \\
\hline Fixed Intercept $\left(\beta_{0}\right)$ & $5.374[\mathbf{4 . 6 9 8}]$ & $0.300[\mathbf{0 . 2 6 9}]$ & $17.91[\mathbf{1 7 . 4 6}]$ & $0.000[\mathbf{0 . 0 0 0}]$ \\
& & & & \\
Random Intercept & $11.211[\mathbf{4 . 2 4 7}]$ & $2.546[\mathbf{1 . 6 0 6}]$ & $4.4[\mathbf{2 . 6 4}]$ & $0.000[\mathbf{0 . 0 0 4 1}]$ \\
$\left(\operatorname{Var}\left(\mathrm{U}_{0 \mathrm{j}}\right)=\sigma^{2}{ }_{u_{0}}\right)$ & & & & \\
\hline
\end{tabular}

$$
\begin{aligned}
& I C C=\frac{\sigma_{u_{0}}{ }^{2}}{\sigma_{u_{0}}{ }^{2}+\sigma_{e}^{2}}=\frac{11.211}{11.211+3.29}=0.7731 \text { for } 2011 \text { EDHS } \\
& I C C=\frac{\sigma_{u_{0}}{ }^{2}}{\sigma_{u_{0}}{ }^{2}+\sigma_{e}^{2}}=\frac{4.247}{4.247+3.29}=0.5635 \quad \text { for } 2016 \text { EDHS }
\end{aligned}
$$

For 2011 EDHS data, the results showed that $77.31 \%$ of the residual variation in the propensity to experience perinatal mortality was attributed to differences between regions. The ICC $=0.5635$ which showed that $56.35 \%$ of the residual variation in the propensity to experience perinatal mortality is attributable to differences between women. 


\section{Models comparison and model fit}

Table 3 shows model comparisons. As it is depicted for all three models the smallest values were observed for random coefficient multilevel model for both 2011 and 2016 EDHS data. Therefore, we used this model for our final data analysis.

Table 3: Model comparison using 2011 [2016] EDHS data

\begin{tabular}{|c|c|c|}
\hline Model & Dbar D(thetabar) & DIC \\
\hline Empty model & $1575.80[1721.47] 1299.68[1491.56]$ & 276.11[229.92] 1851.91[1951.39] \\
\hline Random Intercept & $1333.19[1238.10] 1103.83[1060.61$ & ] $229.36[177.49] 1562.55[1415.58]$ \\
\hline ndom Coefficien & t1201.14[1099.43]1026.84 [937.67] & $174.30[161.77] 1375.44[1261.20]$ \\
\hline
\end{tabular}

\section{Results of Bayesian multilevel random coefficient model}

From the result of the Bayesian multilevel random coefficient model presented in Table 4 below, comparing between gender being the odds of perinatal mortality for female was 0.355 times lower than males according to the 2011 EDHS data. And from 2016 survey data, the the odds of perinatal mortality from female was 0.52 times lower than males. Comparing between delivery places, the odds of perinatal mortality for hospital delivery was lower than home delivery. The odds of perinatal mortality who resided in the rural area was 5.75 times that of urban in 2011 survey data and 0.904 lower than as compared to urban in 2016 survey data. When we compare sources of water, the odds of perinatal mortality for those who drunk piped water was 0.959 and 0.634 lower than those who used other source of water in 2011 and 2016 survey data, respectively.

The odds of perinatal mortality whose family size was greater than five was 3.88 times higher than those whose family size was less than or equal to five in 2011 survey data, whereas 0.53 lower than those whose family size was less than or equal to five in 2016 survey data. In both survey data, the odds of perinatal mortality was high in the larger family size. The odds of perinatal mortality for age of the mothers aged 20-29 years was 0.60 lower than that of age 15-19 years in 2011 survey data. The odds of perinatal mortality for the age of mother 30-39 years was 0.38 lower than that of age 15-19 years in 2011 survey data. Again, the odds of perinatal mortality for the age of mother 40-49 years was 0.414 lower than those whose mother age was 15-19 years in 2011 survey data. In 2016 survey data, the odds of perinatal mortality whose mother age was $40-49$ years was 0.88 lower than whose mother age is 15-19 years old. The odds of perinatal mortality for the 3-6 birth order was 0.61 lower than first and second order in 2016 survey data. The odds of perinatal mortality who have greater than six birth order were 0.67 lower than those who have first and second birth order in 2011 survey data. The odds of perinatal mortality for 
twin birth was 5.35 and 20.97 higher than a single birth in 2011 and 2016 survey data, respectively. The odds of perinatal mortality for cigarette smoking mothers was 3.59 times higher than that of non smoking mothers in 2016 survey data. The regional perinatal mortality variation $\left(U_{0 j}\right)$ and slope (wealth index $\left.=U_{2 j}\right)$ are statistically significant. The intercept showed that there were a significant regional perinatal mortality variation in both 2011 and 2016 EDHS data. The variance of the interaction between the intercept and slopes of the explanatory variables was also significant. The negative sign for the correlation between intercepts and slopes implies that regions with higher intercepts tend to have on average lower slopes on the corresponding predictors. The covariance between the intercept and random slope of wealth index were -25.665 and -17.455 respectively for 2011 and 2016 survey data. This implied that the perinatal child mortality of rich families was lower than poor families by a larger factor at regions for both survey data. The regional variation of perinatal mortality decreased from 26.232 in 2011 to 15.578 in 2016 surveys. This showed perinatal mortality variation across the region was decreaisng over time.

Table 4. Bayesian multilevel random coefficient model results (all results in bracket are for 2016)

\begin{tabular}{|c|c|c|c|c|c|}
\hline Fixed Effect & Coefficient & $\operatorname{Exp}($ Coef $)$ & S.E & Z-value & P-value \\
\hline Constant & $7.978[7.076]$ & $2916[1183]$ & $0.926[1.108]$ & $17.91[17.46]$ & $0.000 *[0.000 *]$ \\
\hline \multicolumn{6}{|c|}{ Sex of child } \\
\hline Male(ref) & - & - & - & - & \\
\hline Female & $-0.439[-0.734]$ & $0.645[.48]$ & $0.185[0.193]$ & $-2.4[-3.8]$ & $0.0082 *[0.000 *]$ \\
\hline \multicolumn{6}{|c|}{ Place of residence } \\
\hline Urban (ref) & - & - & - & - & \\
\hline Rural & $1.749[-2.348]$ & $5.75[.10]$ & $0.389[0.358]$ & $4.5[6.56]$ & $0.000 *[0.000 *]$ \\
\hline \multicolumn{6}{|c|}{ Place of delivery } \\
\hline Home (ref) & - & - & - & - & \\
\hline $\begin{array}{l}\text { Government } \\
\text { hospital }\end{array}$ & $-0.632[-0.545]$ & $0.532[0.58]$ & $0.207[0.369]$ & $-3.1[-1.5]$ & $0.000 *[0.0668]$ \\
\hline Private hospital & $-0.738[-1.75]$ & $0.478[0.17]$ & $0.357[0.634]$ & $-2.1[-2.76]$ & $0.0179 *\left[0.00233^{*}\right]$ \\
\hline Other & $-1.247[-0.20]$ & $0.29[0.82]$ & $0.641[0.235]$ & | -1.95[-0.86] & $0.0256 *[0.17619]$ \\
\hline \multicolumn{5}{|c|}{ Source of drinking water } & \\
\hline \multicolumn{5}{|c|}{ Family size } & $0.000 *[0.00347 *]$ \\
\hline$<=5$ (ref) & - & - & - & - & \\
\hline$>5$ & $\begin{array}{l}1.357[0.43] \\
\text { f mother }\end{array}$ & $3.88[1.53]$ & $0.218[0.224]$ & $6.225[1.911]$ & $0.000 *\left[0.0256^{*}\right]$ \\
\hline $15-19$ (ref) & s. & & - & & \\
\hline $20-29$ & $0.926[-0.21]$ & $0.4[.81]$ & $0.447[0.530]$ & $-2.1[-0.398]$ & $0.01787 *[0.3373]$ \\
\hline $30-39$ & $0.479[-0.92]$ & $0.62[0.40]$ & $0.249[0.56]$ & $-1.924[-1.64]$ & ] $0.0273 *[0.057]$ \\
\hline $40-49$ & $0.534[-2.10]$ & $0.586[0.12]$ & $0.294[0.59]$ & $1.82[3.56]$ & $0.03439 *[0.0003 *]$ \\
\hline
\end{tabular}


$1^{\text {st }}$ and $2^{\text {nd }}($ ref $)$

\section{Birth order}

3-6 order $\quad 0.357[-0.94] \quad .699[0.39] \quad 0.252[0.25]-1.42[-3.56] \quad 0.0778[0.0003 *]$

$>=7$ order $\quad 1.115[0.32] \quad 0.33[1.37] \quad 0.355[0.286] 3.14[1.1] \quad 0.00085 *[0.1492]$

Single (ref)

\section{Child twin}

Twin

$1.677[3.04]$

$5.35[20.97] 0.417[0.364] 4.02[8.4]$

$0.000 *[0.000 *]$

Not used

\section{Contraceptives}

Used

\section{Religion}

$0.223[-0.28] \quad 1.25[.754] \quad 0.684[0.59] \quad 0.326[0.48] \quad 0.3722[0.3373]$

Orthodox(ref)

Protestant $\quad 0.003[0.97] \quad 1[2.64] \quad 0.287[0.307] 0.01[3.2] \quad 0.496[0.00097 *]$

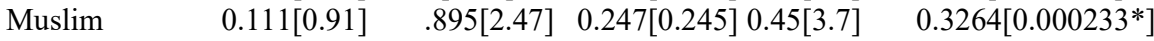

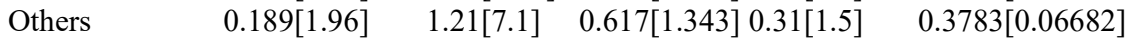

None (ref)

Education level

$\begin{array}{llllll}\text { Primary } & 0.156[0.11] & 0.86[1.11] & 0.232[0.249] & 0.67[0.43] & 0.25143[0.3373] \\ \text { Secondary } & 0.451[0.01] & 1.57[1] & 0.575[0.388] & 0.784[0.026] & 0.21653[0.46931] \\ \text { Higher } & 0.197[-0.61] & 1.22[0.54] & 0.607[0.472] & 0.325[1.29] & 0.3726[0.10384]\end{array}$

Higher $\quad 0.197[-0.61] \quad 1.22[0.54] 0.607[0.472] 0.325[1.29] \quad 0.3726[0.10384]$

No(ref)

Yes

\section{Smoking}

\section{Random Effect}

Var(U_0j) 6.232[15.58]

$0.59[3.59] \quad 0.896[0.501] 0.594[2.55] \quad 0.2763[0.00213 *]$

$\operatorname{Var}\left(\mathrm{U} \_\mathrm{j}\right) \quad 6.113[20.08]$

$5.947[3.495] 4.411[4.46] \quad 0.000 *[0.000 *]$

$\operatorname{Cov}\left(\mathrm{U}_{-} 0 \mathrm{j}, \mathrm{U} \_\mathrm{j}\right)-25.67[-17.45]$

$5.057[5.434] 5.164[3.7] \quad 0.000 *[0.000 *]$

* indicates Significance at $5 \%$ level of significance, ref =reference category (first category).

\section{DISCUSSION}

In this study we applied multilevel model in a Bayesian setting to assess and compare the demographic and socio-economic determinant factors of perinatal mortality and account perinatal mortality heterogeneity among the regions (Adewuyi and Lamichhane 2016). Three different multilevel models such as Bayesian random intercept only multilevel models, Bayesian random intercept multilevel model and Bayesian random coefficient multilevel model and model comparison results depicted that random coefficient multilevel model is best fit the data very well. We also found that the perinatl mortality proporion is least in Dire Dawa, Addis Ababa and Amhara which is similar whith the study (Ashenafi Senbeta et al., 2016). In the 
beginning, we included fourteen demographic and socio-economic determinant factors and chose those predictors which have statistically significant effects on perinatal mortality.

The odds of perinatal mortality for a child who was born from a rural household is higher than a child born from urban household in 2011 survey data. This finding is consistent with the results of previous study (Adewuyi and Lamichhane 2016; Kidanemariam Alem and Habtamu Gebremariam, 2016; Adedini et al., 2015). Sex of the child was significant determinant factor of perinatal mortality in both 2011 and 2016 survey data. Comparing between child's sex, for male the odds of perinatal mortality was higher than female and this result is supported by the previouse study in (Mbiba,2016 ). Similarly, the factor wealth index is an important determinant factor of perinatal mortality in both survey data. Perinatal mortality of a child from low income household were higher than a child from high income household. This result was consistent with the findings of (Adewuyi and Lamichhane, 2016; Yirgu Robel et al., 2016; Adedini et al.,2015).

The result in this study also depicted that place of delivery has significant effect on perinatal mortality in both survey data. Children who were born at home have higher risk of mortality than those who were born at governmental hospital and private hospital in 2011 survey data and this result is consistent with the findings of (Diallo, 2012; Adedini et al., 2015). The study also indicated that birth type (twin or single birth) has significantly associated with perinatal mortality. From the result, perinatal mortality for twin birth is higher than single birth children in both survey data and the result is consistent with findings of (Heino et al., 2010; Andargie Gashaw et al., 2013; Sabzehei et al., 2017; Dahiru, 2017).

Another statistically significant factor associated with perinatal mortality was source of drinking water. The perinatal mortality of a child from a mother who used piped source of water has less risk of mortality as compared to mothers who used other sources of drinking water in both survey data and this finding is consistent with (UN, 2013; Ezeh et al., 2014; Adewuyi et al., 2017). The perinatal mortality of a child from a mother aged 15-19 is higher than a child from a mother aged 20-29, 30-39 and 40-49 for 2011 survey data and this result is inconsistent with the findings of (Agrawal and Bhatnagar, 2017; Fuster, 2016). Family size was also a significant determinant factor of the perinatal mortality. The results showed that in large family size (greater then five) the perinatal mortality is higher than small family size in both 2011 and 2016 survey data. Moreover, birth order was also the significant determinant factor in this study. Hence, in both 2011 and 2016 survey data, the perinatal mortality is higher than in the first and the second birth order. This finding is supported by the study (Adewuyi and Lamichhane, 2016). In 2016 survey data, perinatal mortality is higher for children from cigarette smoking mother compared with children from non-smoking mother and this result was similar with the findings of (Usynina et al., 2017). From the result of Bayesian multilevel empty model we 
found that the perinatal mortality heterogeneity between regions for both 2011 and 2016 survey data. From the final model, the regional variation of perinatal mortality is decreasing from 26.232 in 2011 to 15.578 in 2016 surveys. This showed that perinatal mortality variation across the region is decreasing over time. This study is consistent with the findings (Ashenafi Senbeta et al., 2016; Adedini et al., 2015).

\section{CONCLUSION}

The purpose of this study was to identify the determinants of perinatal mortality and to assess regional variations of perinatal mortality in Ethiopia; by using Bayesian multilevel model. The study identified some socio-economic, demographic and environmental proximate variables as determinants of perinatal mortality in Ethiopia using 2011 and 2016 EDHS data. Among all determinant factors used in this study; sex of child, wealth index, place of delivery, place of residence, family size, birth order, source of drinking water, age of mother and child twin were found significant determinant factors of perinatal mortality in both 2011 and 2016 survey data.

A child from higher age mother was less likely experienced the perinatal mortality than those with age group 15-19 in both survey data. Again, the perinatal mortality was higher in the large family size than small family size in both survey data. The result also showed that the twin birth has higher perinatal mortality than single birth in both 2011 and 2016 survey data. The mothers who delivered at home were more likely experienced perinatal mortality than those who delivered at governmental hospital, private hospital and other health center in 2011 survey data. A child born from a cigarette smoking mother during pregnancy were more likely to experience perinatal mortality than those who were born from non smoking mother in 2016 survey data. It was found that both data best fit in Bayesian multilevel random coefficient model. In addition from the empty model the overall variance of constant term was found to be statistically significant in both data, implying the existence of variation in perinatal mortality across regions in Ethiopia. The regional variation were higher in 2011 survey data than variation in 2016 survey data. We found that the regional variation of perinatal mortality is 26.232 in 2011 and 15.578 in 2016 surveys. This suggested that there existed regional perinatal mortality variation and the regional variation was decreased from 2011 to 2016 survey data.

\section{Abbreviations}

MCMC : Markov Chain Monte Carlo

EDHS: Ethiopian Demographic and Health Survey

CSA: Central Statistical Agencies 
WHO: World Health Organization

\section{ACKNOWLEDGMENTS}

The authors would like to thank Dr. Abebe Admass from the Department of Linguistics and Development studies, Bahir Dar University for his constructive comments in the language development of this manuscript. The authors also would like to thank the Ethiopian Central Statistics Agency for providing us with all the relevant secondary data used in this study.

\section{REFERENCES}

Adedini, S.A., Odimegwu, C., Imasiku, E.N.S., Ononokpono, D.N and Ibisomi, L. (2015). Regional variations in infant and child mortality in Nigeria: A multilevel analysis. Journal of Biosocial Science 47(2): 165-187.

Adewuyi, E, Zhao, Y and Lamichhane, R. (2016). Socioeconomic, bio-demographic and health/behavioral determinants of neonatal mortality in Nigeria: A multilevel analysis of 2013 demographic and health survey. International Journal of Contemporary Pediatrics 3(2): 311323.4. DOI: https://www.ijpediatrics.com/index.php/ijcp/article/view/239

Adewuyi, E.O., Yun, Z and Reeta, L. (2017). Risk factors for infant mortality in rural and urban Nigeria: Evidence from the national household survey. Scandinavian Journal of Public Health 45(5): 543554. DOI: https://doi.org/10.1177/1403494817696599

Agrawal, M and Bhatnagar, K. (2017). Maternal determinants affecting perinatal mortality: A multivariate statistical approach. International Journal of Reproduction, Contraception, Obstetrics and Gynecology 6(3): 1053.

Andargie Gashaw, Yemane Berhane, Alemayehu Worku and Yigzaw Kebede (2013). Predictors of perinatal mortality in rural population of Northwest Ethiopia: a prospective longitudinal study. $B M C$ Public Health 13(1): 168. DOI: https://doi.org/10.1186/1471-2458-13-168

Ashenafi Senbeta, Tilahun Ferede, Aklilu Toma and Amanuel Disassa (2016). Variations in under-five child mortality among regional states of Ethiopia: A multi-level modelling approach. Current Journal of Applied Science and Technology 15(2): 1-16. DOI: 10.9734/BJAST/2016/24448.

Central Statistical Agency (2011). The Federal Democratic Republic of Ethiopia, Central Statistical Agency. Analytical report on the 2016 EDHS. Addis Ababa, Ethiopia.

Central Statistical Agency (2016). The Federal Democratic Republic of Ethiopia, Central Statistical Agency. Analytical report on the 2016 EDHS. Addis Ababa, Ethiopia.

Dahiru, T. (2017). First-day and early neonatal mortality in Nigeria: A pooled cross-sectional analysis of Nigeria DHS data. Journal of Advances in Medicine and Medical Research. pp.1-12. DOI: $10.9734 /$ BJMMR/2017/28247

Diallo, A.H. (2012). Perinatal and infant mortality in rural Burkina Faso: A prospective community-based cohort study. Dissertation for the degree of philosophiae doctor (PhD), University of Bergen, Norway.

Ezeh, O.K., Agho, K.E, Dibley, M.J., Hall, J and Page, A.N. (2014). The impact of water and sanitation on childhood mortality in Nigeria: Evidence from demographic and health surveys, 2003-2013. International Journal of Environmental Research and Public Health 11(9): 9256-72. DOI: https://doi.org/10.3390/ijerph110909256

Fuster, V. (2016). Biodemographic Analysis of Factors Related to Pre-natal Mortality in Portugal (19882011). International Journal of Pediatrics, Volume 2016, Article ID 6123065. DOI: https://doi.org/10.1155/2016/6123065

Heino, A., Gissler, M., Hindori-Mohangoo, A.D., Blondel, B., Klungsøyr, K., Verdenik, I., Hox, J., 
Mirjam, M and Van de Schoot, R. (2010). Multilevel analysis: Techniques and applications. Routledge.

Hoff, P.D. (2009). A first course in Bayesian statistical methods. Springer, New York.

Johnson, B.D. (2010). Multilevel analysis in the study of crime and justice. In: Handbook of quantitative criminology. pp. 615-648. Springer, New York. DOI: https://doi.org/10.1007/978-0387-77650-7 30

Khan, H.R and Shaw, E. (2011). Multilevel logistic regression analysis applied to binary contraceptive prevalence data. Journal of Data Science 9: 93-110.

Kidanemariam Alem and Habtamu Gebremariam (2016). Logistic regression analysis on the determinants of stillbirth in Ethiopia. Maternal Health, Neonatology and Perinatology 2(1): 10. DOI: https://doi.org/10.1186/s40748-016-0038-5

UN (2013). The millennium development goals report 2013. United Nations Publications. https://www.un.org/millenniumgoals/pdf/report-2013/mdg-report-2013-english.pdf $\quad$ (accessed March 27, 2021).

Mbiba, V. (2016). Factors associated with perinatal mortality in Umguza and Bubi rural areas: The effect of maternal human immunodeficiency virus status. MSc Thesis submitted in partial fulfillment of Master of Public Health, University of Zimbabwe.

Mihiretu Negash and Elazar Tadesse (2017). Perinatal death and associated factors in Wolaita Sodo Referral Hospital, Southern Ethiopia: A facility based cross-sectional study. Primary Health Care 7(269): 2167-1079.

Sabzehei, M.K., Basiri, B., Shokouhi, M and Eghbalian, F. (2017). Perinatal outcome in multiple versus singleton pregnancies in neonates born in Fatemieh Hospital of Hamadan, Iran. International Journal of Pediatrics 5(8): 5493-5500. DOI: 10.22038/IJP.2017.23647.1995

Siddalingappa, H., Nrayana Murthy, M.R., Kulkarni, P and Ashok, N.C. (2013). Prevalence and factors influencing perinatal mortality in rural Mysore, India. Journal of Clinical and Diagnostic Research 7(12): 2796.

Sinha, S., Aggarwal, A.R., Osmond, C., Fall, C.H.D., Bhargava, S.K, Snijders, T.A.B and Bosker, R.J. (1999). An introduction to basic and advanced multilevel modeling. Department of Statistics, University of Pune, India.

UN (2013). The millennium development goals report 2013. United Nations Publications. https://www.un.org/millenniumgoals/pdf/report-2013/mdg-report-2013-english.pdf ～(accessed March 27, 2021).

Usynina, A.A., Grjibovski, A.M., Krettek, A., Odland, J.Ø., Kudryavtsev, A.V and Anda, E. E. (2017). Risk factors for perinatal mortality in Murmansk County, Russia: A registry-based study. Global Health Action 10(1): 1270536. DOI: 10.1080/16549716.2017.1270536

World Health Organization (2006). Neonatal and perinatal mortality: country, regional and global estimates.

Yirgu Robel, Mitike Molla, Sibley, L and Abebe Gebremariam (2016). Perinatal mortality magnitude, determinants and causes in west Gojam: Population-based nested case-control study. PLoS One 11: 7: e0159390. DOI: https://doi.org/10.1371/journal.pone.0159390 